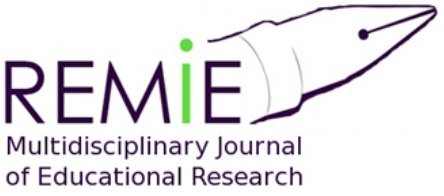

Multidisciplinary Journal of Educational Research

\section{Hipatia Press}

www.hipatiapress.com

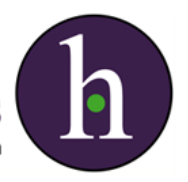

Instructions for authors, subscriptions and further details:

http://remie.hipatiapress.com

\title{
EI Profesor Cosmopolita en un Mundo Global
}

Estefanía Fernández Antón

1) Universidad de Barcelona. España

Date of publication: February $15^{\text {th }}, 2016$

Edition period: February 2016-June 2016

To cite this article: Fernández Antón, Estefanía. (2016). El Profesor Cosmopolita en un Mundo Global. [Review of the book]. REMIEMultidisciplinary Journal of Educational Research, 6(1), 100-102. doi:10.17583/remie.2016.1839

To link this article: http://dx.doi.org/doi:10.17583/remie.2016.1839

\section{PLEASE SCROLL DOWN FOR ARTICLE}

The terms and conditions of use are related to the Open Journal System and to Creative Commons Attribution License (CC-BY). 
REMIE - Multidisciplinary Journal of Educational Research Vol. 6

No. 1 February 2016 pp. 100-102

\section{Review}

Hansen, D. T. (2014). El profesor cosmopolita en un mundo global. Madrid: Narcea. ISBN: 978-84-277-1938-5

El Profesor Cosmopolita en un Mundo Global de David T. Hansen es una obra destinada a los profesores de todo el mundo; siendo su objetivo ayudarles a responder a los retos contemporáneos que están vinculados a una realidad en continuo cambio y en la que viven personas con singularidades individuales y culturales.

En la introducción y en el capítulo número 1 del libro, Hansen nos habla de la perspectiva cosmopolita para alcanzar el fin indicado. Aclarando, a su vez, que se entiende como una perspectiva porque es una forma de mirar y pensar que lleva a actuar de una determinada manera.

En el cosmopolitismo el profesorado educa siguiendo miradas, pensamientos y actuaciones solidarias que son proyectadas en la gente de todo el mundo. El autor señala que preocuparse por un mundo, más allá del propio, favorece la apertura a nuevos conocimientos que deben ser comprendidos desde lo conocido y la reflexión. Otra idea vinculada a esta aportación es que no se trata de olvidar los esquemas previos, sino de transformar aquellos que sean necesarios mediante la reflexión y los valores.

La filosofía del arte de vivir, es el tema principal de los dos siguientes capítulos. En el primero de ellos se explica de manera detallada este corriente, que contiene propósitos cosmopolitas.

Estos propósitos son identificados en las aportaciones de Confucio, Sócrates, Platón, John Dewey, Alain Locke, Erasmo de Rotterdam, Diógenes, Tagore, Epicteto, etc. Por lo tanto, desde una mirada a la historia, el profesor aprende que el conocimiento de la condición humana, así como su respeto, son el origen de la responsabilidad social. Esta última 
se tiene que enseñar y aprender como un propósito que da sentido a la vida de las personas.

En definitiva, se está haciendo alusión a cambiar el prisma personal; este cambio consiste en entender que las personas tienen que encontrar que la humanidad se entiende como tal y encuentra armonía en la comunidad y no en el individualismo.

El tercer capítulo, se centra -entre otros- en unos de los rasgos más particulares de la condición humana: la velocidad con la que cambian los valores.

Esta situación debe entenderse por el profesorado como una oportunidad para enseñar que todos debemos estar unidos ante el cambio; de esta manera, la respuesta hacia la incertidumbre no será desde la desesperación. Esta unión tiene sentido porque el cambio continuo es algo que hemos compartido las personas a lo largo de la historia.

En el capitulo número 4, el cosmopolitismo se entiende como una pedagogía basada en la creatividad cultural. Sobre la creatividad cultural ya hemos hablado, más específicamente, en la parte en la que exponíamos que los aprendices tienen que interaccionar con lo nuevo sin perder de vista la reflexión y lo conocido. En esta expansión del conocimiento individual entra en juego la forma de expresar los valores (pacífica, deliberativa, violenta, etc.), y es en la expresión de los valores donde cada individuo muestra su nivel de relación con el cosmopolitismo. Una relación de cercanía con esta perspectiva se encuentra en conservar los valores propios, mantenerlos en el tiempo y transformarlos mediante la absorción de otros nuevos en espacios diferentes.

En la última sección del libro, vemos como se ofrece las instituciones educativas formales como espacios donde cultivar las finalidades cosmopolitas (que hemos ido viendo a lo largo de los capítulos indicados). La importancia del cosmopolitismo en las aulas y la forma de plantarlo se puede entender mejor a partir un ejemplo que resume, una vez más, desde las acciones de una profesora, que en la interacción con el legado cultural se encuentra el aprendizaje de la realidad.

No podemos terminar sin decir que es un libro que se une a la filosofía para educar al profesorado de cada presente. Entonces hablamos de un libro sin fecha de vencimiento. También es un libro que apuesta por orientar a los 
102 Fernandez Antón - El Profesor Cosmopolita [Book Review]

docentes del mundo a cultivar el cosmopolitismo, en las aulas, a través de un camino basado en la reflexión que se plasma en dos preguntas que tienen que ser respondidas por cada uno de nosotros: ¿quién soy? ¿En qué deseo convertirme?

Estefanía Fernández Antón, Universidad de Barcelona fanita1fernandez@gmail.com 